\title{
A problemática da identidade cultural nos museus: de objetivo (de ação) a objeto (de conhecimento)*
}

\author{
Ulpiano T. Bezerra de Meneses \\ Diretor do MP/Universidade de São Paulo
}

Identidade: uma noção problemática

\section{va a UNESCO:}

Na Declaração de Políticas Culturais de 1982, no México, afirma-

"Cada cultura representa un cuerpo único e irremplazable de valores, puesto que las tradiciones y formas de expresión de cada pueblo se constituyen en su manera más efectiva de demostrar su presencia en el mundo. Por ello mismo, la afirmación de la propria identidad contribuye a la liberación de los pueblos. Por el contrario, cualquier forma de dominación constituye una negación o impedimento para alcanzar dicha identidad" lapud Laumonier 1993:37).

No mundo dos museus, declarações como essa tinham largo curso e imediata aplicação. Com efeito, desde a década de 60 que se estava procurando resgatar um passado de funções homologatórias e conservadoras e o tema da identidade cultural aparecia como rota capaz de conduzir os museus, com segurança, ao porto almejado. Um dos documentos do ICOM/Conselho Internacional de Museus, de alguns anos mais tarde (Buenos Aires, 1986) mostra a centralidade do problema da identidade cultural, para preencher as responsabilidades que o museu assume, como fator de transformação social:
* O núcleo deste texto, mais reduzido e sem aparato crítico, apareceu nos Anais do III Forum Estadual de Museus - RS, Santa Maria, UFSM, 1992:1726, sob o túlo "Identidade cultural e museus: uma relação problemática".

\footnotetext{
"Su función no se limita ya en transmitir un mensaje universal para una audiencia amorta, sino que debe centrarse en poner la población local en contacto con su pro pria historia, sus tradiciones y valores. Por medio de estas actividades el museo con-
} 
tribuye a que la comunidad tome conciencia de su propria identidad que generat mente le ha sido escamoteada por razones de orden histórico, social o racial, o que se ha ido desdibujando bajo la presión de la centralización o la urbanización" (apud Laumonier 1993:391.

A eleição da identidade cultural como um dos objetivos fundamentais que o museu deveria perseguir (reforçando identidades frágeis, consolidando as desestruturadas, recriando as desfeitas, protegendo as ameaçadas) levou a que a questão fosse sempre acriticamente considerada e que trabalhar a(s) identidades(s) se transformasse numa palavra de ordem. É verdade que o caráter seletivo da identidade era às vezes reconhecido (como ocorre na própria continuação do último documento transcrito), mas sua natureza, enquanto fenômeno social, era simplesmente ignorada. Daí considerar-se a identidade como uma substância, quintessência de valores e qualidades a priori positivas, imunes a qualquer crivo. E o museu como seu santuário.

Não há como negar que, enquanto ação política, tais posturas deixaram um saldo positivo. No entanto, já é mais que hora de aprofundar o conhecimento do fenômeno da identidade (fazendo apelo à contribuição das ciências sociais, principalmente da Psicologia Social e da Antropologia) a fim de evitar os inúmeros descaminhos que sua desconsideração provocou no domínio do patrimônio cultural, em geral, e dos museus, em particular.

Convém começar, porém, pelo exame de algumas conotações etimológicas da expressão.

A raiz da palavra identidade é expressiva. O grego idios se refere a "mesmo", "si próprio", "privado". O derivado "idiota", por exemplo, indica a quintessência da mesmidade, a impossibilidade de um indivíduo compreender o que se passa fora do quintal de sua experiência privada.

Em conseqüência, a identidade pressupõe, antes de mais nada, semelhanças consigo mesmo, como condição de vida biológica, psíquica e social. Ela tem a ver mais com os processos de reconhecimento do que de conhecimento. Assim, os conteúdos novos não são facilmente absorvidos quando a identidade está em causa, pois o novo representa, aí, descontinuidade do referencial, logo, ameaça, risco. Do ritmo (repetição), ao contrário, decorre sempre segurança: os batimentos cardíacos compassados, a circulação normal, o passo regular, etc., correspondem a sinais tranquilizadores, que qualquer alteração compromete. E. Zerubavel (1989) ao estudar a necessidade psicológica e social das alternâncias constantes, chegou a cunhar a expressão homo rythmicus. A Psicologia Social tem ressaltado nos fenômenos de representações sociais o papel determinante da "ancoragem", mecanismo que permite a incorporação do novo por enraizá-lo em algum conteúdo previamente dominado e do qual ele pareceria ser apenas um prolongamento (cf. Moscovi 1990; Jodelet 1989).

Aliás, a socialização, entendida como forma de criar identidades sociais dos indivíduos, é que garante a reprodução da estrutura social (CookGumperz 1983:1231. 
Por estas razões todas, a afirmação de identidade está vinculada a necessidades de reforço. Com isso manifesta-se inquestionavelmente sua característica tendência conservadora.

Além do mais é preciso salientar seus compromissos na construção de imagens, campo fértil para a mobilização ideológica e as funções de legitimação em que determinadas práticas obtêm aceitação social. Assim, p.ex., a identidade pessoal é indispensável como suporte de status. A imagem que o indivíduo faz de si mesmo será utilizada para justificar ou reclamar uma certa partilha de direitos e obrigações. Por isso, ela só terá eficácia se obtiver convalidação externa, se houver aceitação social. Assim, na "apresentação do eu", as pessoas "negociam" ou se acomodam às circunstâncias sociais, nesse theatrum mundi que Goffman (1971) tão bem carácterizou. Com maior razão a identidade social depende das imagens construidas de forma a assegurar o indispensável endosso da sociedade (Weinreich 1983).

Daí a tendência de tais imagens (particularmente no caso das identidades nacionais) escamotearem a diversidade e, sobretudo, as contradições, os conflitos, as hierarquias, tudo mascarando pela homogeneização a posteriori e por uma harmonia cosmética. Observe-se, pois, como ela pode facilmente servir para alimentar as estratégias de dominação e desempenhar funções anestésicas (cf. Ortiz, 1985; Queiroz 1989).

Em suma, a visão simplista com que se tem tratado no campo cultural a questão da identidade encobre graves problemas, que é preciso trazer à tona.

Identidade, semelhança, diferença

Se a identidade tem como foco a semelhança, ela produz, em contrapartida, a diferença: a afirmação de semelhança necessita da oposição do que não é semelhante. Frederik Barth (1968), por exemplo, explora nessa linha o conceito de "identidade contrastiva". Em conseqüência, a identidade forçosamente não apenas deriva das diferenças, mas precisa explicitá-las e exarcebálas. O semelhante é inofensivo, inócuo. É o diferente que encerra risco, perturba. Assim, a diferença está na base de todas as classificações, discriminações, hierarquizações sociais. Em outras palavras, não se precisam as diferenças apenas para fins de conhecimento, mas para fundamentar defesas e privilégios:

"representation of otherness participates in the production and reproduction of social inequality. The culture of difference is a hierarchical culture" (Pieterse 1991:2011.

Em suma, identidade e poder não se dissociam.

Qualquer rápido olhar sobre a situação mundial contemporânea confirma esta importância de ameaça e dos conflitos de interesse no aguçamemto e no surgimento/ressurgimento da identidade. Não são outras as variáveis presentes em áreas de confronto, de matriz étnica patente: País Basco, Irlanda do Norte, Oriente Médio, ex-lugoslávia, ex-União Soviética e assim por diante - além do renascimento, inclusive entre nós, dos separatismos, racismos e estigmatizações culturais. 
Identidade e dinâmica sócio-cultural

A identidade não é uma essência, um referencial fixo, apriorístico, cuja existência seja automática e anterior às sociedades e grupos - que apenas os receberiam já prontos do passado. Não existe um conteúdo ou grau ideal de identidade. "Perda da identidade", assim, é uma expressão enganadora - e bem diversa da crise de identidade, de que fala Erickson (1980:132), ou da perda de condições de formular/reformular a identidade. Muitas vezes, tal expressão apenas mascara o fenômeno da mudança sócio-cultural. Da mesma forma, "resgatar a identidade" é objetivo impossivel de atingir. Como recuperar algo que não é estático, não tem contorno definitivo, pronto e acabado, disponível para sempre? Com efeito, não só a identidade é um processo incessante de construção/reconstrução, como também ganha sentido e expressão nos momentos de tensão e ruptura - precisamente quando se aguça a percepção da diferença e sua presença se faz mais necessária. Assim, não existe identidade em abstrato. A identidade só pode ser identificada "em situação". Sem historicização e análise de conjunturas precisas é inconseqüente o estudo de referências culturais, p.ex. nos movimentos separatistas (cf. Abélès 1980:35).

A identidade não é, pois, fruto do isolamento de sociedades ou grupos mas, pelo contrário, de sua interação. Ela é crucial quando existem segmentos sociais que não se pensam como totalidades únicas /Carvalho 1983:201.

Aliás, nem a construção do "eu", nem a do "outro", produzem entidades discretas - e opostas - mas subsistem apenas dialeticamente. O outro, diz Van Alphen (1991:3), na dimensão do exótico, é a visão negativa daquela que o próprio observador tem de sua identidade. E continua:

"The other is not the description, not even an interpretation of reality, but the formulation of an ideal, desired identity. In the case of nationalism, descriptions of the other are phantasms of the potential enemy, not interpretations of a real one in any sense (...) the other has no objective existence outside the interpreter's perception".

Além disso, a identidade se fundamenta no presente, nas necessidades presentes, ainda que faça apelo ao passado - mas é um passado também ele construído e reconstruído no presente, para atender aos reclamos do presente. Por isso é que um historiador como Hobsbawm (1984) tanto insistiu na "invenção"das tradições.

Identidade e segmentação social.

Se se ignorar o que dizem as ciências sociais sobre a diferenciação social nas sociedades complexas, corre-se o risco de falar de identidade cristalizada, no singular - ilusória, portanto, já que desconhece os segmentos sociais, sobretudo as próprias classes sociais. Isto não quer dizer que deva sem- 
pre existir uma correspondência entre uma classe social e uma imagem de identidade específica. Nem que a identidade da classe dominante seja a identidade dominante, mecanicamente (Chesko 1992:45)

A situação é muito mais complexa. Por ora, basta ressaltar que, se quisermos nos afastar da ilusão de uma totalidade íntegra e coesa, teremos que forçosamente enfrentar o problema das divisões e do conflito. Roberto Cardoso de Oliveira (1976, 1983), por exemplo, demonstra como, em nossa situação histórica, não há como admitir identidade étnica fora dos sistemas interétnicos. Ele propôs o conceito de "fricção interétnica"(por certa analogia com a luta de classes), para respeitar a relação dialética que articula etnia e classe social e ressaltou o papel da ideologia (cujo núcleo é a identidade), mascarando relações efetivas que se dão no nível da estrutura social.

Deixando de lado o problema mais amplo de estrutura e das classes sociais, é bom chamar a atenção para outras segmentações menores, mas muito importantes - na ótica dos museus - pelo uso discriminador de objetos. Pode ser lembrado o estudo de Hedbige (1974), que buscou analisar, na Inglaterra, esse fenômeno da compartimentação de culturas e o uso contestatório, dentro dela, das expressões materiais. Examinando as práticas e representações de hippies, punks, skinheads, hooligans, etc. lque ele trata como subculturas, segmentos da cultura que procuram negá-la), propôs-se identificar as funções desempenhadas pelo "estilo", enquanto apropriação de certos objetos e procedimentos como signos de identidade proibida ou como fontes e portadores de novos sentidos: jaquetas de couro, adornos metálicos, broches, pintura corporal e padrões corporais de expressão, penteados, música, etc., etc. Nisso tudo ele viu um repto à hegemonia cultural, em que as contradições e objeções são expressas indiretamente pelo estilo e, assim, resolvidas apenas imaginariamente. Em decorrência, na contracultura a identidade se afirma sobretudo pelo estilo, aglutina-se na revolta, na recusa, na contraposição. Fenômenos como esses não podem ser ignorados na compreensão da identidade.

Os museus e o problema da identidade sócio-cultural

A teatralização da vida social e suas implicações nos processos de identidade é tema que tem recebido atenção cada vez maior (cf. Goffman 1971, como uma das referências iniciais). Seria interessante, por isso mesmo, dar mais atenção à importância, nesses processos, da visibilidade, da sensorialidade. Isso nos encaminha para o campo dos museus - que se caracterizam, precisamente, pela prioridade que neles têm as coisas materiais e pela possibilidade de explorá-las não só cognitiva, mas também afetivamente. Em suma, os museus dispõem de um referencial sensorial importantíssimo, constituindo, por isso mesmo, terreno fértil para as manipulaçōes das identidades. Seria ocioso lembrar com que facilidade certos objetos se transformam em catalisadores e difusores de sentidos e aspirações: da cruz do cristianismo aos uniformes mili- 
tares, passando pelas bandeiras nacionais e pelos emblemas publicitários. Tratase, efetivamente, de fetiches de identidade, de alto poder de comunicação.

Já se salientou como, no Ocidente, a idéia de identidade está associada à de coleta e acumulação de posses - "a kind of wealth lof objects, knowledge, etc. $)^{i}$, no dizer de Clifford (1985:238). Em linha semelhante, analisando documentos da UNESCO (como os mencionados no início deste artigol, Handler (1991) demonstrou contundentemente a persistência do individualismo possessivo postulado por Macpherson, e que leva, afinal, a valorizar políticas culturais nas quais, em última instância, "being depends upon having"(ib.:69).

Território das identidades, os museus são pois percebidos como recurso estratégico a seu serviço. A exposição, em especial, tem sido vista como "privileged arenas for presenting images of self and other" (Karp 1951:15; ver também Abranches 19831.

Seria ingênuo imaginar a ausência, aqui, das molas do poder. Aliás, Donald Horne (19.84), em livro muito difundido, demonstrou o papel fundamental dos museus na legitimação do poder e do imaginário da Europa, desde a consolidação das nacionalidades, no século passado.

Por sua vez, é explícita a demanda de jovens nações, de utilizar os "museus nacionais". para alimentar seu próprio projeto de identidade ("projeto", obviamente, pressupõe pré-existência com relação à identidade). Patrick Boylan (1990) deixou, a esse respeito, testemunho esclarecedor. Ao organizar o Museu do Quatar, logo depois de sua Independência, ele registrou que, segundo os dirigentes da nova nação, quatro eram as prioridades de governo, expressamente formuladas, pela ordem: organização de um sistema de defesa, criação de um museu nacional, organização de um sistema de comunicações, criação de uma universidade. Esta não é uma operação neutra. Escusado dizer que, a fim de alimentar a imagem da nação, o museu alimenta também suas reivindicações - melhor dizendo, menos as reivindicações da sociedade, que as do estado e seus suportes. Essa operação impõe que se eliminem as diversidades e tensões e que se reduza toda uma realidade complexa e dinâmica a um referencíal fixo, simples, dotado da capacidade de captar algo como uma substância permanente, uma essência imune a mudanças e que se torna visível no "típico". Daí a reificação dos objetos, sua coisificação, fetichização. Isto é, cria-se a ilusão de que eles é que se relacionam uns com os outros e exprimem conteúdos próprios e não os das sociedades e grupos cujas interrelações é que os produzem, mobilizam e thes dão sentido -sempre em alteração constante. No museu, o risco é que uma exposição, por exemplo, se transforme em apresentação de coisas, das quais se podem inferir paradigmas de valores para os comportamentos humanos e não na discussão de como os comportamentos humanos produzem e utilizam coisas com as quais eles próprios se explicam. Com a agravante de que o típico acaba, facilmente, transformado em estereótipo (cf. Ames 1986 ) - gerado, sempre no seio de uma relação de forças (para um exemplo ilustrativo, sobre o "tipicamente nordestino", ver Penna 19921. 
Ora, tudo o que veio exposto até aqui poderia parecer um libelo contra os processos de identidade e, em particular, contra sua presença negativa no campo dos museus. No entanto, o que se quis ressaltar foi apenas o caráter problemático das questões da identidade, caráter de que o museu ainda não tomou consciência profunda, mormente nas implicações para as práticas museológicas. Não é possivel minimizar a necessidade dos processos de identidade, que constituem, como se disse no início, requisito essencial de vida biológica, psíquica e social. Todavia, as múltiplas dimensões do fenômeno é que não podem ser perdidas de vista.

Em outras palavras, o que se deve propor é que os museus tenham sempre e obrigatoriamente uma postura crítica em relação à problemática da identidade.

Museus e identidade: premissas para uma postura crítica

Sem a postura crítica, portanto, facilmente os museus se deixariam embaraçar numa rede ideológica. Conviria, consequentemente, refletir melhor sobre alguns tópicos aptos a orientar esse esforço de análise e entendimento.

Numa tipologia sumária, podem-se distinguir três níveis principais de amplitude na atuação dos museus: o universal, o nacional e o local/regional. O primeiro, por certo, se apresenta como distante do viés ideológico da identidade. Isto, porém, está longe de ser verdadeiro, embora, no caso, tal viés seja menos articulado e aparente. Aliás, basta examinar alguns dos grandes museus da espécie (Louvre, British Museum, Dahlem, Metropolitan ...) para concluir que a própria pretensão à universalidade é já um sintoma de etnocentrismo. Este modelo enciclopédico, porém, já não é hoje o mais difuso e não deve ocupar nossa atenção, ainda que ele tenha repercussões importantes nos museus de arte contemporânea e nos de ciência e tecnologia, que postulam uma universalidade de condição.

Já o museu de horizontes nacionais é o que maior risco corre, em particular por sua necessidade de dar conta de uma suposta totalidade, a nação. Ocorre, assim, comumente, que ele passe a privilegiar o estereótipo (ver Dundes 1983:250ss.), por sua capacidade de expressar a quintessência do típico: roupas, alimentos, armas, utensílios, objetos domésticos, de aparato e cerimoniais, equipamentos, imagens e situações, tudo se organiza disciplinadamente e a diversidade apenas dá mais cor ao núcleo estável da identidade nacional. Por já ter existido no passado, esta deve continuar indefinidamente sua existência. Nos museus históricos, tal perspectiva obriga a sínteses já discutíveis como forma de conhecimento histórico ("História Nacional" ...) e cujo resultado, muitas vezes, equivale ao de enciclopédias ilustradas que dão ordem, forma e sentido a um universo caótico e trepidante de contradições (ver Leon \& Rosenzweig, eds. 1989; Schlereth 1992:303-415; Walsh 1992).

Ao contrário, julgo que seria obrigação primordial de um museu, não fornecer o "lípico" para consumo, mas condiçōes para que se possa enten- 
der como, numa sociedade, se constrói a tipicidade, como se formulam nos diversos lugares sociais e se articulam entre si (inclusive hierarquicamente) os inúmeros vetores materiais emblemáticos de objetos, práticas e valores, e como estes conteúdos "típicos" e seus suportes são utilizados, funcionam e mudam.

Com maior razão, tratamento semelhante deve ser reservado aos estereótipos. Conviria, aí, recorrer às contribuições da Etnopsicologia (cf. Kohn 1974:2011, cuja tarefa principal é a análise crítica das representações do conhecimento vulgar, de referência étnica ou nacional.

O museu local/regional seria aquele em que os processos de identidade encontrariam o espaço mais aceitável de expansão. Entretanto, não há por que exclút-los dos riscos. Não há, em nossa sociedade, realidade regional/local que seja homogênea e estática. Daí o perigo de tais museus exercerem papéis compensatórios de refúgio para simbolicamente "recuperarem" uma unidade perdida ou (o que é pior) de espelhos em que narcisisticamente se procure a devolução da imagem que já tinha sido atribuída a si próprio - e que agora retorna sedutora, pronta a se transformar num termômetro com o qual se mede (etnocêntricamente) toda a realidade. G.H. Rivière, o grande mentor do museu socialmente responsável e inspirador dos ecomuseus, sempre chamou a atenção para estes desvios, seja do museu-refúgio, seja do museu-espelho (cf. Raphaël \& Herbérich-Marx 1987:87).

Como conclusão, importa reiterar que não cabe aos museus serem depositários dos símbolos litúrgicos da identidade sagrada deste ou daquele grupo, e cuja exibição deve induzir todos à aceitação social dos valores implicados. Cabe, isto sim - já que ele é o espaço ideal para tanto -, criar condições para conhecimento e entendimento do que seja identidade, de como, por que e para que ela se compartimenta e suas compartimentações se articulam e confrontam, quais os mecanismos e direções das mudanças e de que maneira todos esses fenômenos se expressam por intermédio das coisas materiais. A formulação de Hainard me parece pertinente para indicar a direção deste esforço: deve-se ir ao museus para interrogar e se interrogar, não para buscar respostas já concluídas.

A identidade e a prática dos museus

É preciso fazer justiça e reconhecer que, já há algum tempo, muitos dos problemas aqui referidos têm preocupado os museólogos e aberto vários caminhos de superação. Ainda que parciais e insuficientes, não podem ser desconsideradas as propostas formuladas e experimentadas. Valeria a pena examinar algumas delas.

Uma das linhas é a da "desmusealização" dos acervos. Com esta expressão refiro-me aos casos mais simples de devolução de peças a seus contextos originais (embora tais contextos possam ser também museológicos), como - retorno pelo governo italiano à Albânia da estátua da deusa de Butrinto ou o recâmbio, à Alemanha, de peças subtraídas por soldados americanos durante a 
última guerra - para citar dois entre muitíssimos outros casos (Greenfield 1989; Robinson 1980|.

Refiro-me, porém, em especial, à reapropriação de peças para usos não museológicos. Assim, em 1976, a entrega aos Krahô, por comodato, de uma machadinha incorporada desde 1947 às coleções do Museu Paulista da USP atendeu a alegações de sua importância para cerimônias essenciais na configuração da identidade cultural do grupo. Nos Estados Unidos, Canadá, Austrália, Nova Zelândia, têm sido freqüentes exemplos comparáveis; em muitos casos, a devolução se refere a despojos funerários (Handler 1991; Hamú 1981, 1990; Jones 1993, Jones et alii 19931.

Trata-se de um verdadeiro movimento, iniciado há mais de duas décadas, que tem a impulsioná-lo várias entidades, organizadas principalmente nos Estados Unidos e Canadá, como o North American Indian Rights Fund, a North American Indian Museums Association ou a Assembly of First Nations. Nos Estados Unidos, aliás, os resultados têm sido consideráveis: desde 1978 o Código de Ética da AAM/American Association of Museums incluiu dispositivos referentes à manipulação de objetos sagrados e restos ósseos -dispositivos precisados e ampliados posteriormente e constantes de políticas formais. Em 1990 foi promulgado o The Native American Graves Protection and Repatriation Act, cujo enunciado já revela bem a amplidão e propósitos abrangidos. A UNESCO também tem participado destes debates lque, pela sua complexidade, ficam aqui apenas apontados) e formulado propostas, como as encaminhadas pela reunião de Atenas, 1991, do Comitê Intergovernamental Para a Promoção do Retorno de Bens Culturais a seus Países de Origem.

Outra modalidade é a cessão do acervo e local para cerimônias ou situações de práticas originais: sirva de ilustração a execução de atos religiosos pelos Maori no Hawkes Bay Museum (Nova Zelândia), atendendo a todas as regras culturais, inclusive a interdição da presença de mulheres e de não-Maori (Lowenthal 1992:26).

Diga-se de passagem que estas exclusões - previstas, como se disse acima, nos processos de identidade - têm sido objeto de ressalvas. Com relação aos mesmos Maori, diz Adrienne Kaeppler lapud Karp \& Lavine, orgs. 1992:2):

"Are Maoris and their heritage to be considered separate from ... other Pacific islanders who make New Zealand their home? Will museums be on the forefront of cultivating new kinds of identity and educating the population about them? ... Should they echo the political climate or should they be a force of change?"

Estas questões não podem ser levianamente respondidas - e não há propósito, neste texto, em aprofundá-las. Basta mencionar que a exclusão foi sempre a norma. Talvez o exemplo mais retumbante, triunfalista - e sedutor seja o do Museu de Antropologia do México que, apesar de seu caráter nacional, não apenas exilou, obviamente, os espanhóis conquistadores, mas também os negros e os imigrantes (García Canclini 1989: 171-2).

A incorporação, para projetos comuns, de minorias ou representantes daqueles grupos que definem os horizontes a serem cobertos pelos 
museus, é outra linha em curso. Predomina nos museus antropológicos, mas está presente também em museus de outra tipologia, como os de arte contemporânea (cf. Karp \& Lavine, orgs. 1991; Ames 1990).

O Museu Goeldi apresentou em Belém e no Rio uma exposição Kayapó que teve, na responsabilidade de sua organização, a presença dos próprios indígenas, o que determinou marcas fundamentais - e positivas - no resultado (Oliveira \& Hamú, orgs. 1992).

Desta forma, têm surgido várias exposições segundo a ótica do representado, como as mostras organizadas por Goswamy (Karp 1990:21), de arte indiana, e estruturadas segundo o conceito estético indiano de rasa (baseado na resposta emocional direta). Doutra parte, há propostas de sistematizar os pré-requisitos para este reconhecimento, nos museus, do "outro" como sujeito. Ames, por exemplo (1986 e, sobretudo 1990) ressalta a importância de desfazer certos binômios redutores, como arte/artefato, passado/presente e assim por diante.

Estas experiências se têm multiplicado em várias partes do mundo. De certa forma, o projeto dos ecomuseus se insere nesta vertente - embora por vezes dificultada pela conceituação do que seja a "comunidade"que é, ao mesmo tempo, objeto e sujeito do museu.(Para uma caracterização geral, ver Hudson 1992).

Uma terceira vereda procura levar às últimas conseqüências o debate relativo ao "direito à História". A quem pertence a História? Quem está legitimamente capacitado para produzi-la e utilizá-la? Já se vê que a questão de fundo é o controle do universo do sentido: problema de alcance político central, que os museus não podem deixar de encarar de face (ver Handler 1991; Meneses 1993; Messenger, org., 1989; Gathercole \& Lowenthal 1990; Layton org., 1989; McBride, org. 1985).

Nessa ótica é que minorias "documentadas" em museus passaram a exigir que não só a formação de coleções e a organização de exposições e outras atividades contassem com a assessoria e colaboração de seus representantes, mas que toda a gestão institucional fosse de sua exclusiva responsabilidade. Daí a distinção que começa a operar-se (p. ex., nos Estados Unidos, Canadá, Austrália, etc.) entre museus antropológicos e museus étnicos.

Todas estas alternativas são muito amplas e de graves conseqüências para serem discutidas sumariamente, aqui. Limito-me apenas a apontar questões que necessitarão de urgente aprofundamento e estudo sistemático.

Em primeiro lugar, é preciso reconhecer que elas expressam saudáveis reivindicações políticas e, com isso, acentuam a dimensão social do museu, projetando luz sobre questões que permaneceram durante muito tempo numa injustificável inconsciência. Contudo, os efeitos colaterais podem ser tão danosos quanto os do mal que se queria combater: as experiências acima lembradas não são eficazes para resolver, no museu, o inevitável confronto com o "outro", o conhecimento e a aceitação da alteridade, embora removam algumas formas repressoras da alteridade.

Lowenthal (1952) observou que, desejando superar o elitismo, muitas vezes os museus caíram no populismo e no paternalismo. A necessária 
contestação do saber acadêmico que se apresente como o único objetivo e inatacável não pode resumir-se ao pólo oposto (e, ao final das contas, equivalentel de monopolizar como definitivo o saber subjetivo, interno aos grupos, propostos como a única instância válida para dizer (todas) as coisas pertinentes sobre si mesmo (ver, para discussão sobre "olhar interno" e o "olhar externo", Augé 19891.

Conviria, para finalizar, tentar uma aproximação no debate destas questões pertinentes aos museus, com aquelas que têm sido levantadas nas disciplinas afins, em particular a História e a Antropologia, quanto à produção do conhecimento. Afinal, o problema do conhecimento é crucial em ambos os contextos e deslocar o foco de interesse, de sua natureza e fundamentos internos, para o de sua legitimidade formal, é ressuscitar o argumento de autoridade. Ora, é necessário combater toda pretensão a monopólio e toda tutela sobre o conhecimento, seja do vencedor ou do vencido, da minoria ou da maioria, do observador ou do observado.

A História começou a preocupar-se tardiamente com o problema do "outro", que é o foco destas discussões. Hoje, todavia, a disposição de dar voz aos silentes e excluídos tem provocado uma fragmentação generalizada, que corre o risco de atomizar o campo da disciplina. São inúmeras as variantes temáticas e metodológicas: História "vista por baixo", Micro-história, História Antropológica, História do cotidiano, História Oral, História das muIheres, das crianças, etc. etc. etc. (para um panorama, ver Burke 1991). Excluídos os frutos dos modismos e a ocorrência de descompromissos com a insubstitúvel dialética entre as macro e as micro-estruturas, é evidente o benefício que essa introdução da dimensão da "experiência vivida" trouxe ao conhecimento histórico.

No entanto, nenhuma justificativa haveria, por isso, para imaginar que o papel do historiador fosse, apenas, o de providenciar assepticamente canais para a fiel expressão dos agentes da História lagora nos dois sentidos, de processo e operação cognitival. Seria confundir o dado com a informação -nível puramente empírico, que necessitaria de processamento adequado para transformar-se em conhecimento. Por outro lado, se tal conhecimento, que não é objetivo, também não for inter-subjetivo, mas permanecer mergulhado na subjetividade, escaparia a qualquer avaliação crítica - a única garantia de validade. Paralela a estas questões é a da memória que, pelas mesmas motivações sociais (e políticas) já se propôs como equivalente à História. Hoje, parece-me aceito que a Hlstória não deva ser o duplo científico da memória, o historiador não possa abandonar sua função crítica e a memória precise ser tratada como objeto da História (Meneses 1992).

A Antropologia, por tratar de um "outro" predominantemente vivo, tem contribuição mais rica a fazer (cf. Segalen org. 1989). É fundamental á concepção de texto etnográfico lo comparável, em nosso domínio, seria a exposição museológical, vetor de representações culturais de caráter contingente, histórico e sujeito a contestação (Clifford \& Marcus 1986).

Desloca-se, assim, o paradigma da observação para o da interação ("interlocutionary situation", na terminologia de Austin). $\bigcirc$ "outro" não é construí- 
do independentemente do "eu"e vice-versa: "the other is other because s/he is focalized by the self of the observer" (van Alphen 1991:15).

Paralelamente, no terreno museológico, Edwina Taborsky (1990), examinando as limitações do paradigma observacional do conhecimento, propõe a predominância do objeto discursivo para a organizaçãō dos enunciados que o museu produz, na exposição. Esta visão de que o conhecimento se constrói, não previamente circunscrito, fechado, mas na interação observador/objeto, é prenhe de implicações de toda ordem e, por isso, está a exigir atenção e estudo. A Museografia, com efeito, se encontra despreparada para responder, já, a tais exigências (Meneses 1993).

Os problemas aqui apontados, ao invés de encerrarem a discussão apenas abrem novas frentes. Por isso, é que tem sentido encerrar este texto apenas salientando duas questões seminais, que encaminho para a necessária e urgente reflexão ainda por fazer.

A primeira diz respeito ao caráter contingente que deve assumir a exposição, tal como uma monografia, em que estão à mão do leitor todas as cartas que o autor utilizou - e que poderão ser, assim avaliadas. Como introduzir museograficamente tal postura? Como, com os próprios sentidos que a exposição propõe, exibir museograficamente o processo de sua produção?

A segunda questão: a perspectiva discursiva acima apontada como conveniente à exposição implica que a problemática da identidade e da alteridade "should not focus on the intrinsic characteristics of a cultural artefact, but on the interlocutionary situation in which such an object receives its meaning" (van Alphen 1991:51. Como se institui, então, museograficamente, esta interação discursiva - tão mais fértil do que os padrões usuais de exposição interativa, no modelo "hands on", com seus compromissos, em geral, de pura motricidade?

Em um caso e outro, preserva-se a dimensão crítica do museu, tão desprestigiada em nossos dias - mas sem a qual se compromete toda responsabilidade social.

Imagino, por tudo isso, que o museu deva abandonar como exclusivos seja o modelo da torre de marfim da Academia, seja o da trincheira de militância. A imagem mais adequada, penso, seria a da Torre de Observação (a "Outlook Tower" de Patrick Geddes), plantada no coração da cidade, solidária como ela, mas capaz de permitir examiná-la criticamente, como um todo e em suas partes (uma das quais a própria torre), nas suas contradições e descontinuidades, nos seus conflitos e reivindicações divergentes, na sua permanente dinâmica.

Somente assim a afirmação da identidade, ainda que geradora da diferença, deixará de municiar automaticamente as estratégias da dominação.

\section{BIBLIOGRAFIA}

ABÉLÈS, Marc. Le local à la recherche du temps perdu. Dialectiques, Paris:311980 42 , 30, Octobre. 
ABRANCHES, Henrique. Musées et recherche d'une identité culturelle. 1983 In: ICOM'83. Londres, ICOM/UK.

AMES, Michael M. Cultural empowerment and museums. In: PEARCE, Susan $1990 \quad$ M. ed. Objects of knowledge. London, Athlone: 158-173 (New Research in Museum Studies, 1).

AMES, Michael M. How anthropologists stereotype other people. In: 1986 Museums, the public and Antbropology. Vancouver, University of British Columbia Press:38-47.

AUGÉ, Marc. L'autre proche. In: SEGALEN, M. (org.). L'autre et le semblable. 1989 Paris, Presses du CNRS:19-33.

BARTH, Frederik. Los grupos étnicos y sus fronteras. México, Fondo de 1968 Cultura Económica.

BOYLAN, Patrick. Museums and cultural identity. Museums Journal, 1990 London:29-32, 90 (10) October:

BURKE, Peter. (org.) A Escrita da História. Novas Perspectivas. São Paulo, Ed. 1992 UNESP.

CARVALHO, Edgard de Assis. Identidade e etnicidade e questão nacional. In: 1983 Anais do I Encontro Interdisciplinar sobre Identidade. São Paulo, PUC/SP (Bol. do Grupo de Pesquisa sobre Identidade Social, 2, nov.).

CHESKO, Sergei. Problemas etnopolíticos recientes en la ex-URSS. In: HIDAL1992 GO, Cecilia \& TAMAGNO, Lilian, orgs., Etnicidad e Identidad. Buenos Aires, Centro Editorial de América Latina.

CLIFFORD, James. Objects and selves - an afterword. In: STOCKING, Jr., 1985 George W., ed., Essays on museums and material culture. Madison, The University of Wisconsin Press: 236-244.

COOK-GUMPERZ, Jenny. Socialization, social identity and discourse. In: 1983 JACOBSON-WIDDING, ed., 1983: 123-133.

CORBEY, Raymond \& LEERSSEN. Joep, eds., Alterity, identity, image. Selves 1991 and Others in society and scholarship. Amsterdam, Rodopi.

DUNDES, Alan.Defining identity through folclore. In: JACOBSON-WIDDING, 1983 ed., 1983:235-261. 
ERIKSON, Erik H. Identity and the life cycle. A re-issue. New York, Norton \& 1980 Co.

GARCÍA CANCLINI, Néstor. Culturas hibridas. Estrategias para entrar $y$ 1989 salir de la modernidad. México, Grijalbo.

GATEHRCOLE, P. \& LOWENTHAL, D., eds. The politics of the past. London, 1990 Unwin Hyman.

GEDDES, Patrick. Critic survey of Edinburgh. Edinburgh, Outlook Tower. 1911

GOFFMAN, Erving. The presentation of self in everiday life. Harmondsworth, 1971 Penguin.

GREENFIELD. Jeanette. The return of cultural treasures. Cambridge, Cambridge 1989 University Press.

HAMÚ, Denise. The survival of native American values. Indian, claims to 1981 Museums. Washington, George Washington University (dissertação de mestrado em "Museum Studies", ms).

HAMÚ, Denise. A sobrevivência de valores indigenas: as solicitações de repa1990 triação de objetos sagrados e de esqueletos bumanos feitas aos museus. (ms).

HANDLER, Richard. Who owns the past. Cultural property and the logic of 1991 possessive individualism. In: WILLIAMS, Brett, ed., The politics of culture. Washington, Smithsonian Institution Press: 63-74.

HEDBIGE, Dick. Subculture. The meaning of style. London, Methuen. 1979.

HOBSBAWM, Eric. Introdução: A invenção das tradições. In: HOBSBAWM, 1984

E. \& RANGER, T., orgs. A invenção das tradiçôes. Rio, Paz e Terra:9-23.

HORNE, David Donald. The great museum. The re-presentation of History. 1984 London, Pluto.

HUDSON, Kenneth. The dream of the reality. Museums Journal. London: 271992 31, april.

JACOBSON-WIDDING, Anita, ed. Identity: personal and socio-cultural. $A$ 1983 Symposium. Uppsala, Uppsala University. 
JACOBSON-WIDDING, Anita. Introduction. In: JACOBSON-WIDDING ed., 1983 1983:13-32.

JODELET, Denise, org. Les représentations sociales. Paris, PUF. 1989.

JONES, Jane Peirson et alii. Bones of contention. Museums Journal. London: 1993 24-36, March.

KARP, Ivan \& LAVINE, Steven D., eds. Exbibiting cultures. Poetics and politics 1991 of museum display. Washington, Smithsonian Institution Press.

KARP, Ivan. Culture and representation. In: KARP \& LAVINE, eds., 1991:11-24. 1991

KOHN, Igor S. Le problème du caractère national. Revue de Psychologie des 1974 Peuples, Le Havre:193-223, II/III (vol. 29), Janv./Sept.

LAUMONIER, Isabel. Museo y sociedad. Buenos Aires. Centro Editorial de 1993 América Latina.

LAYTON, R. ed., Who needs the past? Indigenous values and Archaeology. 1989 London, Unwin Hyman.

LEON, Warren \& ROSENZWEIG, Roy, eds. History museums in the United 1989 States: a critical assessment. Urbana, University of Illinois Press.

LOWENTHAL, David. From patronage to populism, Museums Journal, 1992 London:24-27, 92, March.

MASCOVICI, Serge, org. Psychologie Sociale. Paris, PÜ.

1990.

MCBRIDE, Isabel, ed., Who owns the past? Melbourne, Oxford University 1985 Press.

MENESES, Ulpiano T. Bezerra de. A exposição museológica: pontos críticos na 1993 prática corrente. Ciências em Museus, Belém, 3 (no prelo).

MENESES, Ulpiano T. Bezerra de. A História, cativa da memória? Para um 1992 mapeamento da memória no campo das ciências sociais. Revista do Instituto de Estudos Brasileiros/USP, São Paulo: 924,34 .

MESSENGER, Phyllis M., org., The etbics of collecting cultural property. 1989 Whose culture? Whose property? Albuquerque, University of New Mexico Press. 
OLIVEIRA, Adélia Engrácia de \& HAMÚ, Denise, orgs. Ciência Kayapó. Alter1992 nativas contra a destruiçâo. Belém, Museu Paraense "Emílio Goeldi".

OLIVEIRA, Roberto Cardoso de. Identidade e estrutura social. Etnicidade e 1983 estrutura de classe. In: Enigmas e soluções. Exercicios de Etnologia e de crítica. Rio, Tempo Brasileiro/Fortaleza, Ed. da UFCE:101-149.

OLIVEIRA, Roberto Cardoso de. Identidade, etnia e estrutura social. São 1976 Paulo, Pioneira.

ORTIZ, Renato. Cultura brasileira e identidade social. São Paulo, Brasiliense. 1985

PENNA, Maura. O que se faz ser nordestino. Identidades sociais, interesses $e$ 1992 o "escândalo Erundina". São Paulo, Cortez.

PIETERSE, Jan Neder veen. Image and power. In: CORBEY \& LEERSSEN, eds., 1991 1991:191-203.

QUEIROZ, Maria Isaura Pereira de. Identidade cultural, identidade nacional no 1989 Brasil, Tempo Social, Revista de Sociologia/USP, São Paulo:2946, 1 (1), 1o. sem.

RAPHAËL, Freddy \& HERBÉRICH-MARX, Genéviève. Le musée, provocation de 198 la mémoire. Ethnologie Française, Paris: 87-94, 17(1).

ROBINSON, Alma. The art repatriation dilemma. Museum News, Washington: 1980 $55-59,58(4)$

SCHLERETH, Thomas J. Cultural History and material culture. Everyday life, landscape and museums. Charlottesville, University Press of Virginia.

VAN ALPHEN, Ernst. The Ohter within. In: CORBEY \& LEERSSEN, eds., 1991: $1991 \quad 1-16$.

WALSH, Kevin. The representation of the past. Museums and heritage in the 1992 post-modern world. London, Routledge.

WEINREICH, Peter. Psychodynamics of personal and social identity. In: JACOB1983 SON-WIDDING, ed., 1983:159-185. 
Museologia, operando em fina sintonia, estão expondo e restituindo à comunidade as informações recuperadas em escavações sistemáticas na área e desta forma garantindo a preservação da sua memória.

UNITERMOS: Arqueologia Histórica. Exposição museológica. Fazendas de café, Vale do Paraíba, RJ., séc. XIX. Modo de vida burguês.

An. MP. NS 1: pg. 179, 1993.

Symptoms of a bourgeois way of life, 19th-- century Paraiba Valley: Fazenda São Fernando, Vassouras RJ (An archaeological and museological exploration).

Tânia Andrade Lima, Maria Cristina Oliveira Bruno e Marta Ferreira Reis da Fonseca In the scope of an archaeological project that deals with the arising of a bourgeois way of life, which came before the establishment of the bourgeoisie itself, coffee plantations from middle 19th century in the Vale do Paraiba are being investigated. The Fazenda São Fernando, located in Massambará, county of Vassouras, RJ, as one of the most conspicuous examples of the rise and fall process of the monoculture in the valley, has been worked out to become one of the places to disclose such past. Archaeology and Museology, acting in concert, are displaying and returning to the community all data recovered through sistematic diggings, thus assuring the preservation of the valley's memory.

UNITERMS: Historical Archaeology. Museological exhibit. Coffee plantations, 19th.- century Paraíba Valley, RJ. Bourgeois way of life.

An. MP, NS 1: pg. 179, 1993

A problemática da identidade cultural nos museus: de objetivo (dẻ ação) a objeło (de conhecimentol.

Ulpiano T. Bezerra de Meneses

Os museus são comumente tidos como poderosos meios de definir e reforçar identidades. $\bigcirc$ autor propõe que ao invés de tais fins ideológicos, eles considerem a identidade como objeto de análise crítica e compreensão histórica. Aponta vários traços problemáticos da identidade, sobretudo na sua estrutura de processo sócio-cultural e nas suas funçōes contrastivas. A seguir, examina criticamente respostas usuais dos museus a reivindicações de identidade lem especial as que pressupõem a superioridade do conhecimento interior ou étnico sobre o acadêmico). Postula-se a necessidade da abordagem crítica, sempre, como única forma de afrontar o tema da alteridade, independentemente das lutas pelo monopólio da verdade. Traça-se, por fim um paralelo entre a mostra museológica e o conceito de "texto discursivo", formulado pela História e pela Antropologia: as exposições não devem ser nem uma representação absoluta, nem uma expressão subjetiva; mas uma construção dialéfica, contigente e contestável - capaz de fertilizar.

UNITERMOS: Identidade (processo sócio-cultural). Museologia. Museus: funções ideológicas versus críticas. An.MP, NS 1: pg. 207, 1993.

Museums and the problematic concept of cultural identity: from objective (of action) to object lof knowledgel.

Ulpiano T. Bezerra de Meneses

Museums are usually seen as valuable means to attain and reinforce cultural identities. The author argues that, instead of such ideological goals, they should consider identity as an object of critical analysis and historical understanding. Several problematic features are pointed out, mainly identily's nature as a socio-cultural process and its contrastive functions. Current answers of museums to identity claims are then critically analyzed lparticularly the alleged preeminence of inner or ethnic knowledge over 
academic knowledge). In any case, critical approach is required as the only way to deal with alterity, regardless of struggles for monopolizing truth. A final parallel is

established between museum displays and the concept of "discursive text" as

developed in History and Anthropology: exhibits should be taken neither as an absolute representation nor as a subjective expression, but as a contingent and

contestable - and all the way fertile - dialectical construction.

UNITERMS: Identity (sociocultural process). Museology. Museums: ideological versus critical functions.

An. MP, NS 1: pg. 207, 1993. 